\title{
CONTROLE, MEDO E DESPREPARO: ESPERAR O QUE DE UMA ESCOLA ESTRANHA ÀS PRÁTICAS DA LIBERDADE?
}

\author{
CONTROL, FEAR AND UNPREPAREDNESS: WHAT \\ CAN BE EXPECTED FROM A SCHOOL STRANGE \\ TO THE PRACTICES OF FREEDOM?
}

\begin{abstract}
CONTROL, EL MIEDO Y LA FALTA DE PREPARACIÓN: ¿QUÉ ESPERAR DE UNA ESCUELA QUE IMPIDE A LAS PRÁCTICAS DE LIBERTAD?
\end{abstract}

\begin{abstract}
Maurício Bronzatto ${ }^{1}$
KLEBER TÜXEN CARNEIRO ${ }^{2}$

EliasAF RodRIGUES DE Assis ${ }^{3}$

${ }^{1}$ Instituto Federal de Educação, Ciência e Tecnologia de São Paulo. Campus Salto/SP -

Brasil

${ }^{2}$ Universidade Federal de Lavras (UFLA). Lavras/MG - Brasil

${ }^{3}$ Pós-Graduação (MBA). Campinas/SP - Brasil
\end{abstract}

\begin{abstract}
Resumo Este ensaio tem como objetivo refletir sobre os principais efeitos dos projetos de lei no. 867/2015 e 193/2016, do "Programa Escola sem Partido", no trabalho cotidiano do professor e na formação do aluno, e realizar algumas análises que patenteiam o equívoco dessa proposição. Alguns motivos evidentes no longa-metragem A Vila, de M. Night Shyamalan, em especial a manipulação e o controle de corpos e consciências pela instauração do medo, além do obscurantismo e o despreparo, são utilizados como elementos alegóricos para discutir os perigos de uma escola estranha às práticas da liberdade. Exibe-se uma revisão da literatura a respeito dos ideais do programa, com a seguinte organização: os aspectos constitucionais dos projetos de lei, suas implicações para o sistema político e, por fim, os impactos ao desenvolvimento do trabalho docente e à formação discente. Procura-se, ainda, desvelar, analisar e desconstruir o entendimento sobre ideologia, aluno, docente e processo formativo presente no texto dos projetos. Conclui-se com a retomada do filme
\end{abstract}


"A Vila" e a discussão dos seguintes aspectos relacionados à tentativa de implantação da "Escola Sem Partido": a negação dos conflitos e dos desejos; a implantação do medo e a manutenção da ignorância como recursos educativos e de controle; o apagamento das diferenças e a manutenção do status quo; e o perigo de uma coletividade que tolhe a manifestação das individualidades.

Palavras-chave: "Escola sem Partido"; Ideologia; Controle; Empobrecimento formativo.

Abstract This essay aims to reflect on the main effects of law projects n. 867/2015 and 193/2016, of the "School without Party Program", in the daily work of the teacher and in the student's education, and to perform some analysis that shows the misconception of this proposition. Some reasons in M. Night Shyamalan's film "The Village", in particular the manipulation and control of bodies and consciences for the establishment of fear, besides the obscurantism and unpreparedness, are used as allegorical elements to discuss the dangers of a school stranger to the practices of freedom. A review of the literature on the ideals of the program is presented, with the following organization: the constitutional aspects of the proposals of law, their implications for the political system and, finally, the impacts on the development of teaching work and student formation. It also seeks to unveil, analyze and deconstruct the understanding of ideology, student, teacher and formative process present in the text of the projects. It is concludes with the resumption of the film "The Village" and the discussion of the following aspects related to the attempt to implement the "School without Party": the negation of conflicts and desires; the implantation of fear and the maintenance of ignorance as an educational and control resources; the deletion of differences and the maintenance of the status quo; and the danger of a collectivism that preclude the manifestation of individualities.

Keywords: "School without Party Program"; Ideology; Control; Formative impoverISHMENT.

Resumen Este ensayo tiene como objetivo reflexionar sobre los principales efectos de los propuestas de ley nº 867/2015 y 193/2016, del "Programa Escuela sin Partido", en el trabajo cotidiano del profesor y en la formación del alumno, y realizar algunos análisis que evidencian el equívoco proposición. Algunos motivos presentes en el largometraje "A Vila", de M. Night Shyamalan, en especial la manipulación y el control de cuerpos y conciencias por la instauración del miedo, además de la oscurantismo y falta de preparación, que se utilizan como elementos alegóricos para discutir los peligros de una escuela que no aprecia a las prácticas de la libertad. Se presenta una revisión de la literatura sobre los ideales del programa, con la siguiente organizacion: los aspectos constitucionales de los proyectos de ley, sus implicaciones para el sistema político y, por fin, los impactos al desarrollo del trabajo docente ya la formación discente. Se busca, un, desvelar, analizar y deconstrucción el entendimiento sobre ideología, alumno, docente y proceso formativo presente en el texto de los proyectos. Se concluye con la reanudación de la película "A Vila" y la discusión de los siguientes aspectos relacionados con el intento de implantación de la "Escuela Sin 
Partido": la negación de los conflictos y de los deseos; la implementación del miedo y el mantenimiento de la ignorancia como recursos educaciones e controle; el borrado de las diferencias y el mantenimiento del status quo; y el peligro de una colectividad que impide la manifestación de las individualidades.

Palavras clave: "Programa Escuela sin Partido"; Ideología; Control; Empobrecimiento FORMATIVO.

\section{INTRODUÇÃo}

Este ensaio tem como objetivo refletir sobre os principais efeitos dos projetos de lei $n^{\circ}$. 867/2015 e 193/2016, do "Programa Escola sem Partido", no trabalho cotidiano do professor e na formação do aluno. Embora as tramitações por Câmara e Senado estejam, no momento, interrompidas, os indicativos políticos parecem apontar para uma interrupção momentânea, o que nos impõe a necessidade de problematizarmos as principais ideias dos projetos e apresentarmos algumas análises que patenteiam o equívoco de sua proposição.

Como introdução e moldura ao desenvolvimento das reflexões, dialogaremos com o conteúdo de A Vila, longa-metragem escrito, produzido e dirigido por M. Night Shyamalan, lançado nos EUA, em 2004. Essa escolha não é aleatória. Da mesma forma que Puig (1998, p. 141), reconhecemos que a linguagem simbólica e alegórica, despretensiosa quanto a "[...] demonstrar e convencer com raciocínios [...]", faculta, à medida que funde ideias e afetividade, um conhecimento mais vivo dos valores - apreensão tão mais eficaz quanto menos sua transmissão se reduz à esfera dos conceitos e razões.

Na sequência, passaremos a uma revisão não exaustiva da literatura sobre a temática, que apresentaremos com esta organização: os aspectos constitucionais dos projetos de lei, suas implicações para o sistema político e, por fim, os impactos ao desenvolvimento do trabalho docente e à formação discente.

Após a revisão da literatura e antes das considerações finais, procuraremos desvelar, analisar e desconstruir o entendimento sobre: 1) ideologia; 2) aluno;3) docente e processo formativo presente no texto dos referidos projetos, tendo em vista a pluralidade de ideias, a diversidade nos modos de ser e estar no mundo e o protagonismo infanto-juvenil em relação à apropriação do conhecimento no espaço-tempo formativo dos domínios escolares democráticos.

Comecemos, então, por $A$ Vila. Emprestemos da expressão artística - comprometida com a estesia, não com a verdade; ocupada em mostrar, jamais em demonstrar (PLAZA, 2003) - o empuxo para alcançarmos outras "margens" formativas, em que a instabilidade, a ausência de controle e a condição de incompletude reforcem em muitos, os que ensinam aprendendo e aprendem ensinando (FREIRE, 2007), a obstinação de recusar a "[...] abreviar com a vida, nos rasos do mundo" (ROSA, 1988, p. 37). 


\section{O Microcosmo de $\boldsymbol{A}$ VILA: CONTROLE, MEdo E DESPREPARO}

O cinema é considerado por muitos a sétima arte. Por associar, entre outros aspectos, os da literatura, da música, da arquitetura e das artes cênicas (THIEL; THIEL, 2009), prodigaliza uma potência formativa peculiar, capaz de afetar, mobilizando e desestabilizando, até mesmo aqueles e aquelas que, de outros modos, dificilmente teriam o interesse capturado para conteúdos de natureza complexa, que requerem a agudeza e a delicadeza do espírito (SILVEIRA; CARNEIRO; ATHAYDE, 2016).

Ao que parece, esse é o caso do filme $A$ Vila. Dirigido pelo prestigiado cineasta indiano M. Night Shyamalan - também diretor de $O$ Sexto Sentido e Sinais -, o filme retrata a história da pequena e bucólica aldeia de Covington, um vilarejo de não mais que cem moradores, cercado por uma floresta nos limites da Pensilvânia atual. Desertores da violência, do sofrimento e da falta de esperança dos grandes centros urbanos dos EUA, um grupo de pessoas, unido por tragédias pessoais em suas famílias, funda uma vila em um local isolado, à procura de segurança e um novo meio de vida. Uma comunidade apartada do progresso e do dinheiro, alheada de tudo e de todos, para a qual tempo e espaço se estagnaram, já que os fundadores, atrás do "paraíso perdido", recriam o contexto e a atmosfera das últimas décadas do século XIX.

Como, porém, seria possível o isolamento social e econômico a uma comunidade incrustada na famigerada macroestrutura, condenada ao desenvolvimento e à mundialização dos mercados? De que modo não se deixar afetar pelo American way of life, absorvido pelos poros com o oxigênio? E, ainda, como perpetuar nos descendentes a inocência pretendida e mantê-los numa espécie de janela do tempo em que o futuro repetiria indefinidamente o passado?

No roteiro de Shyamalan, o vilarejo é controlado por anciãos, o Conselho, espécie de clã que institui de modo unilateral as regras e os costumes que regem a vida de Covington. Um círculo de poder que precisa lançar mão de alguns subterfúgios para perpetuar a heteronomia da coletividade, bem como, sua dependência afetiva, a fim de que as convenções, desprovidas de significados e adesões racionais livres, sigam sendo observadas. A principal convenção é o interdito de ultrapassar os limites do povoado e adentrar a floresta que o circunda, território habitado por estranhas e ameaçadoras criaturas ("aqueles de quem não falamos").

Alguns aspectos suscitados pela trama merecem aqui nossa atenção. O primeiro é a ausência quase absoluta de questionamentos acerca das convenções, produto do assujeitamento que acomete a vila, presente, inclusive, na denominação das criaturas, que, embora continuem a amedrontar e causar perplexidade, jamais são enfrentadas.

O princípio regulador imposto pelo clã visa à manutenção dos votos que fundaram a vila: nem mesmo em sonhos voltarem a tomar parte no que acontece nas cidades. Com esse intento, um meio de vida alternativo, radicalmente diferente do que se via na vida pregressa, é implementado. Um legado a ser transmitido às novas gerações com a mesma inexorabilidade das heranças genéticas. Eis o fim a que os meios - a vitalidade do discurso 
da periculosidade da floresta e a demarcação de limites psicológicos, mais do que geográficos, para que as fronteiras do povoado não sejam violadas - devem se curvar.

A Vila metaforiza um cenário conhecido nas situações em que o governo é exercido de modo antidemocrático. Produto de decisões para as quais se desconsiderou a vontade da maioria, ou esta, sob controle, sequer soube de si, as resoluções, pautadas por interesses pessoais e idiossincráticos de alguns eleitos, oferecem o tecido social a que os demais devem emaranhar os fios de sua existência, dissolvendo-os na coletividade.

É justificável o princípio da segurança como proibição de ultrapassar os limites da vila, mas não o obscurantismo das razões fornecidas para o comprometimento da segurança caso alguma transgressão seja perpetrada. Menos ainda justificável é a sacralização de um interdito cuja perenidade, como numa religião de mistérios, depende da renovação, de tempos em tempos, da confraria especial de guardiões. Tudo estabelecido de antemão e de uma vez por todas, como vicejaria algum tipo de subversão que poderia dar à luz estratégias de enfrentamento das terríveis criaturas? Adestrados o pensamento e a cosmovisão, o produto, segundo Lima (2011, p. 4), não é outro senão "[...] a inação, a passividade e a acomodação, o imobilismo e a irresolução".

Mas como ocorre na realidade, o microcosmo de Covington tem pessoas e eventos que "atrapalham" a normalidade da vida. Um dado dia, um morador, Lucius, vítima de uma tentativa de assassinato, necessitado, portanto, de assistência médica, põe à prova a autossuficiência da comunidade isolada. Ivy, sua pretendida, prontifica-se a cruzar a floresta proibida e buscar ajuda externa, mesmo sabendo que a aventura significará confrontar aqueles a quem não era permitido sequer nomear. A tradição estava prestes a ser desafiada.

Não sem controvérsias, o Conselho concede autorização a Ivy, por certo fiado no fato de que ela é cega de nascença, logo supostamente incapaz de ameaçar as convenções e os segredos guardados a poucas chaves: mesmo que lograsse êxito, as novidades e seduções da cidade, sem janelas por onde entrar na jovem, não alcançariam sua consciência e afetos. Note-se que, à despedida, Ivy é prevenida pelo pai, um dos anciãos, de que as criaturas apavorantes da floresta não passavam de invenção do Conselho - uma farsa inócua, segundo ele - para manter a inocência do povoado.

Segue-se a travessia, verdadeira odisseia, da qual Ivy regressa não apenas com os insumos médicos para salvar o amado Lucius, à beira da morte. Carrega também o espanto pela solidariedade de um policial a quem pediu socorro, algo inusitado para ela, habituada, desde a infância, a esperar comportamento totalmente diverso das pessoas da cidade.

Com esses elementos em vista, podemos passar agora a uma breve revisão da literatura científica na qual os projetos de lei $\mathrm{n}^{\circ}$. 867/2015 e 193/2016 estiveram no centro do debate. Na última seção, dedicada às conclusões, retomaremos os motivos de $A$ Vila para dar notas finais ao ensaio.

\section{OS IDEAIS DO PROGRAMA "ESCOLA SEM PARTIDO" - UMA REVISÃO DA LITERATURA}

Embora não seja exaustiva nem sistemática, tampouco recorra ao rigor metodológico de estudos da natureza do "estado da arte", a revisão que realizamos contribui para apresen- 
tar, com alguma consistência, o cenário da tentativa de implantação do "Programa Escola sem Partido" nos sistemas de ensino de educação básica em nosso país.

Em termos de organização, reunimos as produções em três agrupamentos temáticos: 1) os aspectos constitucionais dos projetos de lei; 2) suas implicações para o sistema político; e, finalmente, 3) os impactos ao desenvolvimento do trabalho docente e à formação discente.

\section{OS ASPECTOS CONSTITUCIONAIS DOS PROJETOS DE LEI}

Neto e Cardoso (2017) ocuparam-se da liberdade de cátedra e da autonomia universitária. Após o estudo do conteúdo jurídico-pedagógico desses princípios, concluíram que a limitação à liberdade de ensino defendida nos projetos é inconstitucional.

Numa perspectiva semelhante, Costa (2017) se deteve sobre a constitucionalidade da liberdade de cátedra, procurando evidenciar como os ideais do "Movimento Escola Sem Partido" (MESP), ao ofenderem o direito fundamental de liberdade de pensamento científico, tornam a escola um espaço privado para a reprodução de valores morais e religiosos que, por efeito, inviabilizam debates de questões de relevância política, econômica e social. Conclui tratar-se de projeto de lei inconstitucional que viola a Constituição Federal de 1988, dada sua incompatibilidade com o Estado Democrático de Direito.

Na mesma direção, a investigação de Costa e Pelet (2017) centrou-se na neutralidade científica docente em relação ao debate político das questões de gênero na escola. No entendimento dos autores, os projetos de lei são inconstitucionais, seja por violar a liberdade de cátedra, seja por infringir o direito fundamental à liberdade sexual e estimular o preconceito, a segregação e a marginalização de pessoas que manifestam diferentes orientações de gênero.

\section{AS IMPLICAÇÕES POLÍTICAS DOS PROJETOS DE LEI}

Baldan (2017) objetivou compreender o "Programa Escola Sem Partido" a partir da tese neoliberal e neoconservadora propagada por diferentes grupos que se aglutinam em torno do apanágio de "ódio à democracia", assim como a partir das ações que têm sido implementadas na sociedade brasileira, especialmente no campo educacional.

Na mesma linha, Macedo (2017) dedicou-se a entender como a emergência do MESP e de suas demandas conservadoras deslocaram as negociações políticas na elaboração da Base Nacional Comum Curricular. A autora procurou estabelecer nexos contextuais entre as ingerências do referido movimento e a elaboração da BNCC.

Silva, Dickmann e Bernartt (2017), por sua vez, procuraram correlacionar a deposição política da ex-presidente Dilma Rousseff e os efeitos da política do sucessor, com destaque para seu posicionamento neoliberal, a julgar pelo achatamento do Estado e a violência do "apagamento" dos direitos sociais, notadamente no campo das políticas educacionais.

Dresch (2017) buscou identificar as tendências político-partidárias vinculadas ao MESP, mapeando os partidos que o apoiaram, bem como, os elementos discursivos utilizados pelas "vozes" políticas do movimento. O autor concluiu indicando possíveis implicações para o contexto político e educacional brasileiro e refletindo sobre a importância da atuação democrática do professor. 
Analisando as implicações para a educação e a democracia, Miguel (2017) discutiu criticamente os projetos de lei, suas justificativas e os debates que se seguiram.

Fernandes (2017) procurou traçar o percurso político-legislativo do MESP no município de Campo Grande, capital do Estado do Mato Grosso do Sul, até a aprovação da Lei $n^{\circ}$. 8.242/2016. Posteriormente, dada à grande mobilização social rejeitando a aprovação da lei, o processo jurídico-legal sofreu reversão e se encontra suspenso.

Merece também destaque a obra de Frigotto (2017), cujo objetivo foi destacar o sentido ideológico e político do MESP. Os diversos artigos que o autor coligiu sinalizam a natureza autoritária do programa, que se afirma na criminalização das concepções de conhecimento histórico e formação humana que interessam às questões minoritárias, numa demonstração de intolerância e ódio contra os movimentos sociais.

OS IMPACTOS DOS PROJETOS DE LEI AO DESENVOLVIMENTO DO TRABALHO DOCENTE E À FORMAÇÃO DISCENTE

A análise de Ramos e Stampa (2016) buscou avaliar o debate sobre o controle do trabalho docente e, por conseguinte, do currículo escolar. Os autores traçam um paralelo entre o programa "Escola sem Partido" e alguns aspectos dos ideais da ditadura militar brasileira (1964-1985), numa tentativa de compreender um hipotético cenário em que as proposições do MESP venham a triunfar.

Freitas (2017) procurou discutir as implicações do MESP para a formação humana, argumentando que o referido movimento é um instrumento da falsa formação, já que por força de lei um professor pode ser incriminado caso sua prática seja associada a algum tipo de doutrinação. Destacou, ainda, que colocar a prática docente em suspeição não é algo novo, mas um expediente encontrado nas tendências do projeto histórico da atual civilização. Para Freitas, os ideais da "Escola sem Partido" alinham-se a uma visão de formação tecnicista, voltada apenas à instrumentalização para o trabalho, e não para o mundo do trabalho, insuficiente, portanto, para a transformação da cultura compreendida como feito humano.

Salles (2017), por sua vez, propôs uma análise dos perigos representados pelas propostas e formas de atuação do MESP para a educação brasileira. Como alternativas de resistência, o autor apresenta as perspectivas de educação em Gert Biesta (2012), ao formular critérios que constituem uma boa educação, dos quais um bom exemplo é a função da subjetivação do processo de ensino-aprendizado trabalhando em favor da constituição de um projeto de educação democrática.

Reis, Campos e Flores (2016) contrapuseram as aspirações do MESP às noções que vêm sendo tecidas pelo campo de estudos do currículo quanto à autoria de professores e alunos nos processos de ensino-aprendizagem e na produção do conhecimento.

Já o ensaio de Oliveira, Cerny e Ávila (2018) discutiu como o MESP torna-se uma estratégia de controle do trabalho docente, na medida em que suas propostas afetam diretamente a autonomia do professor e, por efeito, tolhem as possibilidades de debates e aprofundamentos teóricos junto aos educandos. 
Outra produção relevante é a de Silva (2016), que analisou o uso e as possibilidades da história pública no ensino de história na escola. Levando em conta as diversas formas como o conhecimento histórico circula na sociedade e observando a concepção de cidadania presente em currículos brasileiros de história, o autor constata que o MESP pode caminhar no sentido oposto, pois, não obstante a alegação de neutralidade na abordagem pedagógica, há uma agenda oculta que visa silenciar a voz política dos professores e, por conseguinte, a própria realização do debate público no universo escolar.

Na mesma direção, a dissertação de Moura (2016) investigou o MESP e os projetos de lei por ele propostos, bem como, suas consequências ao ensino de história.

Penna (2017) refletiu sobre os riscos de projetos educacionais conservadores, como os da "Escola sem Partido", e o quanto obstruem uma educação emancipadora, à medida que veiculam narrativas antidemocráticas e deturpam saberes historicamente situados.

Bagdonas e Azevedo (2017) discutiram algumas implicações dos projetos para o ensino de ciências. Entre outras complicações, o ensino de temas como o das origens do universo e da vida, de teor reconhecidamente conflituoso em razão das inconciliáveis concepções científica e religiosa, decerto conturbaria o ambiente pedagógico e, não raro, se desdobraria em intermináveis batalhas judiciais, advertem os autores.

Prata e Souza (2018) analisaram as prerrogativas e os projetos de lei do MESP, sopesando as consequências, especialmente para os educadores, da efetivação de propostas dessa natureza na política educacional do país. Destaque-se que as autoras são promotoras de justiça, e o olhar reprovador que endereçam ao programa e seus efeitos deletérios traz o referendo de quem pode arbitrar com conhecimento de causa sobre a ilegitimidade constitucional do que está sendo proposto.

Guilherme e Picoli (2018), por sua vez, problematizaram a matéria dos projetos de lei no . 867/2015 e 193/2016 a partir dos escritos de Hannah Arendt (2003). Educação e totalitarismo, as funções da escola, a separação entre ensino e educação e a negação da pluralidade e da ação política foram alguns dos temas discutidos. Sem dúvida, a fortuna crítica de Arendt sobre o totalitarismo lança muita luz à compreensão do atual cenário político e educacional de nosso país.

Assentado na mesma perspectiva teórica, Reuser (2017) utiliza o pensamento de Hannah Arendt para analisar o MESP, e então pensar as implicações da tarefa docente para o desenvolvimento do país e da humanidade e para a continuidade do mundo.

Em resumo, a revisão sobre os aspectos constitucionais dos projetos de lei aponta para um mesmo lugar: a inconstitucionalidade de sua proposição. Quanto às implicações políticas, os textos sinalizam o retrocesso e os riscos à democracia, assim como indicam o comprometimento do contexto educacional brasileiro e a atuação democrática do professor. Por fim, as produções sobre os impactos dos projetos de lei ao desenvolvimento do trabalho docente e à formação discente escancaram a inviabilidade da apresentação de saberes científicos e de uma formação cidadã, visto que os componentes curriculares dedicados a esse mote estariam sob constante "patrulha" e "assepsia", impedidos de exibir o contraditório, obstados quanto à contribuição para a formação do pensamento crítico. A propósito, 
o currículo escolar, sob a pretensa alegação de neutralidade pedagógica, restaria esvaziado dos conteúdos responsáveis por qualificar a formação discente e subsidiar o debate público consistente no universo escolar.

Vale ressaltar que, exceto ressalvas pontuais quanto a abusos isolados provocados pela autoridade docente no contexto atual da educação brasileira, nenhum dos 21 textos analisados reconhece a legitimidade dos projetos de lei do MESP, o que denota que tais proposições não se fundamentam nas ciências jurídicas, no conhecimento filosófico e, tampouco, em fundamentos didático-pedagógicos sólidos e científicos. Esse é o assunto da próxima seção, dedicada a desvelar, analisar e desconstruir o entendimento sobre ideologia, aluno, docente e processo formativo presente no texto dos referidos projetos.

\section{O CONTEXTO E ALGUNS ASPECTOS DOS PROJETOS DE LEI}

O movimento político que aqui estamos analisando (ou seria melhor dizer "dispositivo de controle"?) não é exclusividade da realidade brasileira, mas uma tendência mundial, encontrada, sobretudo, em alguns países considerados desenvolvidos, de predominância política conservadora. Vamos a dois exemplos.

Na Alemanha, o movimento Neutral Schools ("Escolas Neutras") desenvolveu um portal eletrônico, na qualidade de projeto-piloto, por meio do qual os alunos são encorajados a denunciar professores que expressem opiniões políticas e promovam debates em sala de aula. Trata-se de uma iniciativa comandada pelo partido de extrema direita, Alternative für Deutschland ("Alternativa para a Alemanha" - AfD), em Hamburgo e no Estado de Baden-Württemberg.

Já nos Estados Unidos, a organização sem fins lucrativos Turning Point USA, organizada por estudantes conservadores, desenvolveu o site Prof. Watchlist ("Lista de Vigilância de Professores") com o objetivo de articular politicamente jovens com igual inclinação política e funcionar como detector de pronunciamentos "insidiosos" de professores.

Essas iniciativas tiveram alguma influência sobre os princípios que fundamentam o “Movimento Escola Sem Partido" (MESP) e os projetos de lei no. 867/2015 e 193/2016.

Um dos arautos do movimento no Brasil é o advogado e procurador Miguel Nagib. $\mathrm{O}$ evento que significou o estopim da militância do advogado em favor da causa envolveu a sua filha e o professor de História dela, o último culpabilizado por comparar, numa das aulas, as trajetórias de vida de São Francisco de Assis e Che Guevara.

Adepto da religião Católica Romana, Nagib, sem um exame mais profundo do contexto, sentiu-se indignado com a atitude do professor e prontamente classificou sua iniciativa como doutrinação, afinal, na perspectiva do primeiro: "As pessoas que querem fazer a cabeça das crianças associam as duas coisas e acabam dizendo que Che Guevara é um santo" (MOURA, 2017, p. 23).

Dois pontos da atitude irrefletida de Nagib precisam ser sublinhados: a não observância criteriosa do contexto - o que, por si só, é fábrica de pretextos - e o ortodoxismo 
religioso que, comumente, tolhe e empobrece a capacidade de análise, produzindo posições unilaterais e maniqueístas.

A despeito das controvérsias e movimentos de resistência, os ideais do MESP vêm ecoando por intermédio de um número crescente de seguidores, numa rápida difusão. Até outubro de 2016, foram contabilizados mais de 40 projetos de lei em câmaras municipais, assembleias estaduais e no Congresso Nacional inspirados direta ou indiretamente pelas ideias que o movimento apregoa (MOURA, 2016).

Em função desse ufanismo e da recente tendência política conservadora, o movimento passou da condição de iniciativa popular a programa, cujo teor forneceu a base teórica para dois projetos de lei que pretendem alterar a Lei de Diretrizes e Bases da Educação (LDB). Trata-se, como já mencionado, do PL 867/2015, de autoria do deputado Izalci Lucas Ferreira, reeleito pelo Partido da Social Democracia Brasileira (PSDB), na Câmara dos Deputados, e do PL 193/2016, de autoria do ex-senador Magno Malta, do Partido da República (PR), no Senado Federal. Conquanto os PLs tenham perdido uma importante batalha política no apagar das luzes de 2018 , seus entusiastas não descansarão enquanto uma nova tramitação não alcançar os objetivos do movimento. A seu favor, e isso não é pouco, as aspirações políticas e o perfil ideológico partidário que a nova configuração do legislativo apresenta. Não restará alternativa às vozes de resistência senão recrudescer.

Reiteramos que os projetos em questão possuem aspirações nada modestas, sendo a modificação da LDB, a carta magna da educação, o alvo principal. A despeito de se autointitular apartidário, o movimento, na prática, desde sua fundação, é apadrinhado por um partido político e motivado por uma inclinação ideológica, o que, torna, portanto, ilegítimo o título da proposta e sua pretensão de combate a uma suposta doutrinação ideológica da parte dos que se lhe opõem.

Não sendo possível tratar de cada um dos artigos e incisos dos PLs 867/2015 e 193/2016, vamos nos ater àqueles que explicitam o entendimento do movimento acerca de ideologia, aluno, docente e processo formativo. Essa compreensão, à luz das ciências da educação, nos ajudará a desconstruir falsas representações e falsos argumentos, mais afeitos a fundamentalismos do que a preocupações formativas que tragam mudanças qualitativas substanciais às práticas educativas.

A análise que nos propomos a realizar, embora dirigida aos projetos de lei, não se baseia na hermenêutica jurídica. Antes, aborda questões de natureza pedagógica, se é que se pode chamar de pedagógicas atitudes reacionárias, de conveniência e conservadorismo retrógrado. Sim, as proposições do MESP se assentam menos em questões e desafios que historicamente afetam o campo da educação - alfabetização e letramento; absenteísmo e permanência; analfabetismo funcional, entre outros - e mais em pormenores irrelevantes que ganham vulto na percepção dos que desconhecem as realidades dos cotidianos escolares. Uma "pedagogia" "que se encanta mais com a rede que com o mar" (MONTENEGRO, 2000).

Comecemos com a ideologia. Vejamos o que os projetos têm a dizer. 
Quadro 1 - Os projetos de lei no. 867/2015 e 193/2016 e a questão da ideologia.

\section{PROJETO DE LEI No. 867, DE 2015 PROJETO DE LEI No. 193, DE 2016}

Art. $1^{\circ}$. Esta lei dispõe sobre a inclusão entre as diretrizes e bases da educação nacional do "Programa Escola sem Partido".

Art. $1^{\circ}$. Esta lei dispõe sobre a inclusão entre as diretrizes e bases da educação nacional, de que trata a Lei no .9 .394 , de 20 de dezembro de 1996, do "Programa Escola sem Partido".

Art. $2^{\circ}$. A educação nacional atenderá aos

Art. $2^{\circ}$. A educação nacional atenderá aos seguintes princípios:

I - neutralidade política, ideológica e religiosa do Estado;

seguintes princípios:

I-neutralidade política, ideológica e religiosa do Estado;

II - pluralismo de ideias no ambiente acadêmico;

III - liberdade de aprender e de ensinar;

II - pluralismo de ideias no ambiente acadêmico;

III - liberdade de aprender, como projeção específica, no campo da educação, da liberdade de consciência;

IV - liberdade de crença;

VII - direito dos pais a que seus filhos recebam a educação moral que esteja de acordo com suas próprias convicções.

VI - educação e informação do estudante quanto aos direitos compreendidos em sua liberdade de consciência e de crença;

VII - direito dos pais a que seus filhos recebam a educação religiosa e moral que esteja de acordo com as suas próprias convicções.

Parágrafo único. $\mathrm{O}$ Poder Público não se imiscuirá na opção sexual dos alunos nem permitirá qualquer prática capaz de comprometer, precipitar ou direcionar o natural amadurecimento e desenvolvimento de sua personalidade, em harmonia com a respectiva identidade biológica de sexo, sendo vedada, especialmente, a aplicação dos postulados da teoria ou ideologia de gênero.

Art. $3^{\circ}$. São vedadas, em sala de aula, a prática de doutrinação política e ideológica bem como a veiculação de conteúdos ou a realização de atividades que possam estar em conflito com as convicções religiosas ou morais dos pais ou responsáveis pelos estudantes.

Art. $3^{\circ}$. As instituições de educação básica
afixarão nas salas de aula e nas salas dos
professores cartazes com o conteúdo previsto no
anexo desta Lei, com, no mínimo, 90 centímetros
de altura por 70 centímetros de largura, e fonte
com tamanho compatível com as dimensões
adotadas.

Fonte: Elaboração dos autores.

A primeira observação diz respeito ao artigo $1^{\circ}$. de ambos os projetos, cujo objetivo é incluir os ideais do MESP na Lei $\mathrm{n}^{\circ}$. 9.394, de 20 de dezembro de 1996, que traça as dire- 
trizes e bases da educação nacional. Há, como se percebe, clara intenção ideológica de que as propostas do MESP deixem o status de "iniciativa popular" e se cristalizem na forma de lei federal, tendo em vista controlar e, consequentemente, punir aqueles que transgredirem seus princípios orientadores. A LDB 9.394/96, que tantas emendas já sofreu, seria afetada por mais essa violação à liberdade.

Já no segundo artigo, também de ambos os projetos, muitas questões mereceriam um exame. Contudo, em virtude dos limites textuais deste ensaio, abordaremos a ideia de neutralidade e, em contraponto, a importância do pluralismo de saberes, sem o qual não se conseguirá desestabilizar o idílico conceito de doutrinação que o MESP apregoa.

Em relação à neutralidade, não é novidade o fato de as atividades humanas estarem permeadas de política e ideologia. A ciência não é exceção, uma vez que o "processo" de elaboração do conhecimento a torna "[...] parcial, subjetiva, condicionada socioculturalmente e psicologicamente" (LEITE, 1994, p. 13). Ora, o telos da escola é fornecer aos indivíduos, com as releituras e ressignificações próprias à dinâmica e organicidade do processo de conhecer, os saberes historicamente situados que a humanidade produziu e produz, afinal "[...] a História em que me faço com os outros e de cuja feitura tomo parte é um tempo de possibilidades e não de determinismo" (FREIRE, 2007, p. 53). Não afeitos, porém, à emancipação e com receio de perder o controle quando as transformações lançam rebentos, resta aos defensores da neutralidade, com sua pretensão de manipular os saberes como quem disseca um corpo inanimado, recusarem-se a problematizar o futuro e militarem por sua inexorabilidade (FREIRE, 2007). Educar, ao contrário, é ajudar os jovens e adultos a "lerem" o mundo à luz da razão, como postulava Kant (1724-1804), e a perceberem-no a expensas do homem sensível, como queria Schiller (1759-1805), o que implica a emancipação de toda forma de opressão e assujeitamento. Eis o porquê de o legado freireano incomodar tanto o MESP: nessa perspectiva, a educação jamais será neutra, e muito menos subserviente, porém fundamentalmente libertadora.

Ao propor a imparcialidade no ensino em detrimento do cultivo da multiplicidade de visões, intercâmbios e experiências entre docente e discente, o que se pretende, na realidade, é desarticular a força transformadora e libertadora que o conhecimento põe em ação. E mais: é fabricar uma ilusão maniqueísta de que haveria uma ideologia boa e outra ruim, quando "[...] a função da ideologia é a de apagar as diferenças [...]" (CHAUI, 2008, p. 109), por exemplo a de classes, fornecendo "[...] aos membros da sociedade o sentimento da identidade social, encontrando certos referenciais identificadores de todos e para todos, como, por exemplo, a Humanidade, a Liberdade, Igualdade, a Nação, ou o Estado" (CHAUI, 2008, p. 109). Como se pode ver, a asserção da neutralidade é um equívoco, visto que iluminaria apenas um lado da questão, subtraindo tanto o direito de aprender quanto o de ensinar outras perspectivas.

Consequência inevitável, haveria enorme prejuízo à pluralidade de ideias. Embora os projetos façam alusão à pluralidade, a pretensa neutralidade acabaria por enfraquecê-la. Não raro, ambientes em que não há respeito e cultivo da diversidade e diferença - sejam elas quais forem - tornam-se inevitavelmente autoritários. Ao excluir do debate formativo 
temas controversos e a pluralidade de perspectivas, tem-se, como consequência, a supressão da liberdade. A propósito, a liberdade de ensinar aparece apenas em um dos projetos (193/2016). No que tramita na Câmara dos deputados (867/2015), tal prerrogativa, estranhamente, foi suprimida.

Um dos procedimentos do totalitarismo, segundo Arendt (1973), é a instauração de uma realidade fictícia - uma ideologia - que, ao alterar e negar a complexidade de fenômenos, elementos e fatos acontecimentais que se manifestam como eventos de transformação do/no mundo (religiosos, culturais, políticos, das sexualidades, entre outros), funda seu domínio sobre a história fabricando um engodo discursivo determinista ao qual todos devem aderir, ou pagar o preço da retaliação e, mesmo, do banimento. Só há lugar para uma ideologia, a "nossa".

Os PLs ancorados nos ideais do MESP instituem um ideal de totalitarismo sustentado pela ficção da "perda do mundo" para o "inimigo", identificado naqueles que pensam de modo diferente. Guardados o contexto e as devidas proporções, trata-se da mesma realidade ficcional que os nazistas empenharam para sustentar a mentira covarde e inescrupulosa de que o mundo era dominado pelos judeus, logo os bons - alemães e assemelhados - deveriam envidar todos os esforços possíveis para fazer recuar tal domínio (GUILHERME; PICOLI, 2018).

Ao rechaçar a pluralidade, o totalitarismo procura instaurar uma falsa representação ancorada na negação e alteração dos fatos. Para tanto, considera ideológico o que é científico, e científico o que é ideológico, desde que a inversão de valores corrobore a manutenção da realidade fictícia construída a pretexto de enfrentar uma suposta doutrinação (ARENDT, 1973). Manobra de igual natureza foi retratada em $A$ Vila. Já vimos como os anciãos, na qualidade de conselheiros, forjaram a existência de criaturas temíveis - "os inimigos entre nós" - a fim de assegurar a manutenção do isolamento e o respeito ao perímetro imposto.

A proposta do MESP, traduzida nos projetos de lei, também veicula uma representação de aluno. O quadro a seguir resume bem de que representação se trata.

Quadro 2 - Os projetos de lei nº. 867/2015 e 193/2016 e a representação de aluno.

\begin{tabular}{|c|c|}
\hline PROJETO DE LEI No ${ }^{\circ}$ 867, DE 2015 & PROJETO DE LEI No. 193, DE 2016 \\
\hline $\begin{array}{l}\text { Art. } 2^{\circ} \text {. A educação nacional atenderá aos } \\
\text { seguintes princípios: }\end{array}$ & $\begin{array}{l}\text { Art. } 2^{\circ} \text {. A educação nacional atenderá aos } \\
\text { seguintes princípios: }\end{array}$ \\
\hline $\begin{array}{l}\mathrm{V} \text { - reconhecimento da vulnerabilidade do } \\
\text { educando como parte mais fraca na relação } \\
\text { de aprendizado; }\end{array}$ & $\begin{array}{l}\mathrm{V} \text { - reconhecimento da vulnerabilidade do } \\
\text { educando como parte mais fraca na relação de } \\
\text { aprendizado; }\end{array}$ \\
\hline $\begin{array}{l}\text { VI - educação e informação do estudante } \\
\text { quanto aos direitos compreendidos em sua } \\
\text { liberdade de consciência e de crença; }\end{array}$ & $\begin{array}{l}\text { VI - educação e informação do estudante quanto } \\
\text { aos direitos compreendidos em sua liberdade de } \\
\text { consciência e de crença; }\end{array}$ \\
\hline
\end{tabular}

Fonte: Elaboração dos autores. 
Os incisos V e VI do artigo $2^{\circ}$. constroem uma imagem discente em condição de vulnerabilidade em relação à aprendizagem - um entendimento, a nosso ver, equivocado. Desde Piaget (1987), sabemos que as ações do indivíduo sobre os objetos e as interações com outras pessoas são de importância fundamental na construção do conhecimento. Num texto dedicado à pedagogia, Piaget (1976) reafirma que as funções essenciais da inteligência são compreender e inventar, isto é, construir estruturas estruturando o real. As investigações que comandou por mais de 60 anos levaram-no à conclusão de que:

[...] estas duas funções são indissolúveis e que, para compreender um fenômeno ou um acontecimento, é preciso reconstruir as transformações de que elas são resultantes, e ainda que, para reconstituí-las, faz-se mister primeiramente elaborar uma estrutura de transformação, o que supõe uma parte de invenção ou de reinvenção (PIAGET, 1976, p. 36).

Piaget subordina a compreensão à invenção, logo à atividade e ao protagonismo daquele que se dispõe a conhecer. "Conhecer é, pois, assimilar o real às estruturas de transformações, e são as estruturas elaboradas pela inteligência enquanto prolongamento direto da ação" (PIAGET, 1976, p. 37). Trata-se, sempre, de uma assimilação, isto é, uma interpretação ensejada pela integração do dado às estruturas de transformações do sujeito, que consistem em organizar o real em ato ou em pensamento, e não apenas em simplesmente reproduzi-lo. Assim, o registro de todo dado exterior supõe a existência de instrumentos de assimilação próprios à atividade do sujeito. Não importa que os conhecimentos já tenham sido estruturados pela linguagem ou pela inteligência dos pais ou dos mestres. Essa assimilação prévia da parte dos adultos não faz tais conhecimentos prontos para simplesmente serem incorporados pela criança, como se o ensino verbal fornecesse tanto os conhecimentos a assimilar quanto os instrumentos próprios a essa atividade. É necessária uma nova assimilação, ou seja, uma reestruturação ou reinvenção com base nas atividades internas do conhecedor.

Além do mais, a concepção de conhecimento como simples descoberta de realidades já existentes é anacrônica, pois remonta a uma imagem - apregoada em grande medida pela "escola tradicional" - de que o aluno, espécie de "boneco de engonço", é uma página em branco, num flagrante desrespeito aos saberes que ele já detém, e em oposição à visão freireana de sujeito ativo e em construção (FREIRE, 2007). A concepção de aluno do MESP nega o protagonismo juvenil, o mesmo que o país inteiro testemunhou em 2016, quando centenas de jovens ocuparam várias escolas de diferentes Estados do Brasil. ${ }^{1}$ No filme $A$ Vila, a personagem Ivy é um bom exemplo de como o protagonismo juvenil, para ter ocasião, precisa superar o desdém, a desconfiança e a pecha de vulnerabilidade sob a qual quase sempre se encontra encerrado.

1 O movimento das ocupações foi a forma de protesto eleita pelos estudantes contrários à reforma do Ensino Médio e à PEC 55, que, à época, encontravam-se em tramitação legal. O movimento tomou conta do país em outubro de 2016 e contabilizou mais de mil escolas ocupadas. Para saber mais, recomendamos: ROSSI, Marina. PEC 241: Com quase 1.000 escolas ocupadas no país, ato de estudantes chega a SP. El País. São Paulo, 25 out. 2016. Disponível em: <http://brasil.elpais.com/brasil/2016/10/24/politica/1477327658_698523. html> Acesso em: 7 de dez. 2018. 
Nem página em branco, nem informações para preenchê-la. Não se trata disso se se quer retirar os alunos do submetimento histórico e emancipá-los. Aquilo de que precisam é acesso a formação de qualidade com produção de sentido. Trata-se, nas palavras de Chaui (2003, p. 12), de "[...] uma relação com o tempo: é introduzir alguém ao passado de sua cultura (no sentido antropológico do termo), é despertar alguém para as questões que esse passado engendra para o presente, e é estimular a passagem do instituído ao instituinte".

E quanto à representação da função docente e do processo formativo a ela associado? Vejamos o que os projetos de lei apresentam.

Quadro 3 - Os projetos de lei no 867/2015 e 193/2016 e a representação do papel docente e do processo formativo

\begin{tabular}{l} 
PROJETO DE LEI No 867, DE 2015 \\
\hline $\begin{array}{l}\text { Art. } 4^{\text {o }} \text {. No exercício de suas funções, o } \\
\text { professor: }\end{array}$ \\
I - não se aproveitará da audiência cativa dos \\
alunos, com o objetivo de cooptá-los para \\
esta ou aquela corrente política, ideológica \\
ou partidária;
\end{tabular}

II - não favorecerá nem prejudicará os alunos em razão de suas conviç̧ões políticas, ideológicas, morais ou religiosas, ou da falta delas;

III - não fará propaganda político-partidária em sala de aula nem incitará seus alunos a participar de manifestações, atos públicos e passeatas;

IV - ao tratar de questões políticas, socioculturais e econômicas, apresentará aos alunos, de forma justa, as principais versões, teorias, opiniões e perspectivas concorrentes a respeito;

$\mathrm{V}$ - respeitará o direito dos pais a que seus filhos recebam a educação moral que esteja de acordo com suas próprias conviç̧ões;

VI - não permitirá que os direitos assegurados nos itens anteriores sejam violados pela ação de terceiros, dentro da sala de aula.

\section{PROJETO DE LEI No 193, DE 2016}

Art. $5^{\circ}$. No exercício de suas funções, o professor:

I - não se aproveitará da audiência cativa dos alunos, para promover os seus próprios interesses, opiniões, concepções ou preferências ideológicas, religiosas, morais, políticas e partidárias;

II - não favorecerá nem prejudicará ou constrangerá os alunos em razão de suas convicções políticas, ideológicas, morais ou religiosas, ou da falta delas;

III - não fará propaganda político-partidária em sala de aula nem incitará seus alunos a participar de manifestações, atos públicos e passeatas;

IV - ao tratar de questões políticas, socioculturais e econômicas, apresentará aos alunos, de forma justa, as principais versões, teorias, opiniões e perspectivas concorrentes a respeito;

V - respeitará o direito dos pais dos alunos a que seus filhos recebam a educação religiosa e moral que esteja de acordo com as suas próprias convicções;

VI - não permitirá que os direitos assegurados nos itens anteriores sejam violados pela ação de estudantes ou terceiros, dentro da sala de aula.

Fonte: Elaboração dos autores. 
Em termos de composição textual, os textos dos PLs reproduzidos no Quadro 3 são muito semelhantes. A diferença fica por conta dos incisos I e V do PL 193/2016, que fazem menção à questão religiosa, e do inciso VI do mesmo projeto, segundo o qual nem mesmo os próprios estudantes poderão transgredir os direitos assegurados nos itens precedentes. $\mathrm{O}$ conteúdo do último inciso nos causa estranheza, afinal a sala de aula é um lugar repleto de heterogeneidade, sendo improvável que não ocorram conflitos de toda sorte. Ou estamos diante de um idílio sobre o que é um aluno, ou se trata de desconhecimento puro e simples do que caracteriza uma sala de aula contemporânea.

A propósito, não seriam os conflitos a força motriz que engendra o desenvolvimento? Tomemos, pois, como exemplo, o plano cognitivo: o conflito gera um desequilíbrio das estruturas mentais, instabilidade momentânea que mobiliza o indivíduo na busca por novas respostas com o propósito de solucionar a "perturbação" e ter de volta o equilíbrio perdido (PIAGET, 1987). Do mesmo modo, os dilemas morais, pela via dos conflitos, possibilitam raciocínios mais sofisticados em direção à autonomia. Negar conflitos, portanto, é demover o professor da condição de propositor de situações que possam desafiar a estabilidade do aluno e incitá-lo à produção de sentidos para o conhecimento. Em outras palavras, é perpetuar sua condição de mero transmissor e reprodutor de informações (KOHLBERG; MAYER, 1972).

A suposta doutrinação dos alunos - realidade fictícia conforme já abordamos - não passa de uma falsa representação em que se altera e nega a complexidade dos fenômenos, elementos e fatos, fazendo a "parte mais frágil" acreditar que os professores tomam decisões e fazem escolhas de modo arbitrário e proselitista. Esquece-se de que os objetos de conhecimento não podem ser concebidos, como muitos gostariam, numa espécie de limbo, imunes a influências do campo intelectual, da realidade socioeconômica em que estão inseridos alunos e professores, da legislação, das instituições e comunidade escolar, da gestão do sistema de ensino e, principalmente, da política, entre outras tantas variáveis que "costuram" o contexto escolar (RAMOS; STAMPA, 2016). Vale lembrar que é fundamental para os discentes que a liberdade amadureça "[...] no confronto com outras liberdades, na defesa de seus direitos em face da autoridade dos pais, do professor, do Estado" (FREIRE, 2007, p. 105-106).

$\mathrm{O}$ teor do documento proposto pelo MESP acaba caricaturando o professor e alardeando a condição de alguém mal-intencionado, predisposto a constranger e oprimir alunos, pouco ou nada inclinado a "[...] querer bem aos educandos e à própria prática educativa [...]" (FREIRE, 2007 p. 141) de que participa. Além disso, propõe o esvaziamento da troca de experiências de aprendizagem. Nesse sentido, "[...] é curiosa a dissociação e incongruência que supõe, às vezes, aplicar um conceito determinado de aprendiz ativo ao aluno e ao mesmo tempo preconizar para o professor o papel contrário" (SACRISTÁN, 2000, p. 172), segundo o qual nem mesmo a expressão da subjetividade se sente à vontade.

Ademais, há no conteúdo dos PLs uma supervalorização da influência docente, como se, de fato, na contemporaneidade, a figura do professor fosse a principal formadora de opinião. Gostaríamos muito que isso fosse verdade, mas a realidade é completamente outra. 
Sabe-se que na sociedade das "celebridades" os indivíduos são mais influenciados pelos canais midiáticos de massa - a julgar pelo sucesso dos youtubers, as influências de esportistas, atrizes e atores famosos, entre outros - do que por pais e educadores. E, sejamos honestos, há um profundo esvaziamento da figura docente no Brasil, fenômeno para o qual a própria ação do MESP vem contribuindo sobejamente. O processo é antigo, as exceções são raras. Nesse sentido, independentemente de posições políticas, rechaçar a "Escola sem partido" é um gesto cívico.

\section{OS PERIGOS DE UMA EDUCAÇÃO ESTRANHA ÀS PRÁTICAS DA LIBERDADE}

Com o objetivo de concluir este ensaio, destacaremos alguns motivos de $A$ Vila que dialogam com os perigos da implantação da "Escola Sem Partido" e patenteiam a impossibilidade do concurso de outra educação, estranha às práticas da liberdade.

Tanto o vilarejo de Covington quanto o programa do MESP possuem uma agenda oculta. Na película, aliás, a "caixa preta" onde dormem os segredos dos anciãos é literal, chegando a merecer alguns closes da câmera de Shyamalan. Em um e em outro caso, há uma tentativa de negação dos conflitos e dos desejos, o que pode ser visto, por exemplo, no caso do filme, na relação dos moradores com "aqueles de quem não falamos". Não falar de algo ou de alguém é, em princípio, manter um distanciamento seguro. Não abordar determinados assuntos "espinhosos" significa, quase sempre, não ter que lidar conscientemente com eles nem estar disposto(a) a passar as próprias certezas em revista. Os espectros, no entanto, seguem existindo e cumprindo sua função de comandar a circunscrição do "reino da segurança", onde se celebra o pacto tácito de nunca "borrar" as fronteiras, aquém das quais se pode continuar a fazer tudo sempre igual.

Porém, a despeito da repressão, os conflitos subsistem. Subsistem porque são inerentemente humanos. As inquietações e as perguntas não podem ser silenciadas: vêm à tona como a flor de pétalas vermelhas - a cor proibida porque identificada com as estranhas criaturas da floresta -, que rasga o solo rente aos degraus da casa e surpreende duas jovens moradoras ocupadas com a rotina matinal de varrer a poeira do alpendre. Não adianta arrancá-la e sepultá-la; outras nascerão. A dor também não pode ser silenciada. Ouvimos, aliás, de um dos anciãos, o mesmo que no início do filme aparece sepultando o filho de 7 anos de idade, a confissão da inevitabilidade do sofrimento: como um cão farejador, ele há de encontrar a todos, não importa o quanto se previnam nem o quanto estejam confinados. Da mesma forma, o desejo abre brechas. Até mesmo nas subjetividades de concreto armado. A tentação da infidelidade conjugal ronda o principal dos anciãos; jovens espraiam suas pulsões mais recônditas de transgressão por meio de uma brincadeira antiga de desafiar o medo nos limites entre o povoado e a floresta; um pacato e lúcido morador não consegue se resignar diante das parcas provisões locais de recursos médicos e possibilidades de tratamento psiquiátrico. Como se vê, a vida gesta os desequilíbrios e impulsiona questionamentos que desencadeiam mudanças. A tentativa de controle é mera ilusão.

A propósito, a manipulação do medo dos moradores, associada à manutenção da igno- 
rância, funciona como recurso educativo e mecanismo de controle. A paz e a tranquilidade artificiais criadas pelo Conselho de anciãos são tributárias do medo permanente de que as criaturas ataquem a vila - como vimos, uma farsa para impedir que a floresta fosse transposta e a cidade e seus encantos estivessem ao alcance dos olhos dos inocentes moradores. $\mathrm{O}$ que pode ser mais obscurantista do que uma escola em que os estudantes são constantemente assediados não por uma pretensa doutrinação, verdadeira fixação do MESP, mas pelo trombetear de vozes de juízo prevenindo contra isso, advertindo contra aquilo, urdindo teorias da conspiração e contaminando a opinião pública? Se a escola se torna um lugar perigoso, ladeada por armadilhas ideológicas e inimigos prestes a violar a ingenuidade das crianças e jovens, que atrativos ela pode oferecer? Aliás, quem são esses inimigos? Os professores?! O medo em circulação nos anos em que a educação brasileira - uma educação seletiva, diga-se de passagem - coxeava de uma das pernas porque o protagonismo do aluno não tinha espaço de expressão já não encheu suficientemente as medidas? Evidentemente, são perguntas retóricas, a que o bom senso facilmente responderia. Mesmo que honestas, já que motivadas por tragédias pessoais, as motivações dos anciãos de Covington não se justificam. E como se justificariam se o que fazem é roubar aos liderados a liberdade de escolha? O cenário distópico que a "experiente" narrativa dos anciãos teceu no imaginário de uma audiência cativa, quando deveria ter se responsabilizado pela emancipação e esclarecimento dessa mesma audiência, tem um fim previsível: o medo e o despreparo. Eis o que esperar da "Escola Sem Partido".

Programa, aliás, de um só partido, o MESP se aplica ao apagamento das diferenças e à manutenção do status quo. A diferença, tal qual no filme "Pink Floyd The Wall" (1982), dirigido por Alan Parker, precisa passar pelo moedor de carnes. As incongruências não são bem-vindas, aquilo que é obtuso necessita perder as arestas. Escola, nessa concepção, é lugar de desfraldar os uniformes; as vozes dissonantes precisam soar afinadas, pois o coro deve cantar em uníssono; as respostas aceitas são as do "cardápio curricular". É assim na vila: há a cor que se deve repugnar como um anátema; convenções a seguir como um credo; perguntas que é melhor não fazer; assuntos sobre os quais é proibido conversar. $\mathrm{Na}$ medida em que tolhe as individualidades, o coletivismo põe em perigo a comunidade. Cena recorrente, a cadeira de balanço em tomadas nas quais aparece sem ocupantes referenda o menosprezo da aldeia de Covington pelas singularidades humanas, estas uma ameaça à manutenção da ordem antiga. Nas duas vezes em que Shyamalan filma alguém preenchendo esse lugar, aparecem ora Noah, cuja perturbação mental, instantes antes, o levou à prática de um crime, ora Ivy, na iminência de cruzar a floresta para buscar socorro médico a Lucius, vítima do ciúme de Noah. As cadeiras ocupadas cumprem um papel importante na história, pois embalam personagens que, em dado momento, passam a perturbar a paz de Covington ao desafiarem as tradições. Noah, em razão de uma tentativa de homicídio, o anticlímax do motivo que levou os anciãos a fundarem o povoado; Ivy, porque em breve irá entrar em contato com a cidade, epifania que pode pôr a perder os esforços do Conselho para recriar o paraíso e mantê-lo com base no imaginário do medo.

Noah, refém de um transtorno mental, é uma peça mal encaixada na engrenagem de 
Covington. Com o desenrolar do filme, vamos percebendo que este "ex-cêntrico" (marginal, portanto) era o único morador consciente da maquinação dos anciãos. Noah constantemente transgride os limites demarcados ao adentrar a floresta e não partilha do mesmo pavor que acomete todos os demais. O modo como o Conselho lida com a irreverência de Noah é reforçando sua imagem pública de idiota e lhe aplicando corretivos. A velha tática de sempre, que ronda agora também, sobretudo, os "excêntricos" professores.

Lucius Hunt, filho de uma das fundadoras, tem olhos prescientes que desconfiam dos segredos sobre os quais se erigiu o povoado. Ele consegue enxergar, por detrás do véu de pureza edênica de algumas pessoas, as paixões humanas com as quais elas travam difíceis batalhas. Não ignora a tristeza no encalço de alguns, a despeito de terem tentado encerrar no passado os seus aguilhões. Lucius, pouco a pouco, passa a questionar a realidade e, movido por preocupações altruístas, dispõe-se a atravessar a floresta em busca de benesses que o desenvolvimento das cidades tornou possíveis - expectativa que é, antes de tudo, a intuição esperneante tentando alargar os horizontes que o confinamento estreitou.

Mas é Ivy, cega de nascença, quem mais parece compreender como o mundo funciona. Ivy enxerga com o coração, por isso vê bem, por isso vê o essencial. Inverossímil que possa parecer, a jovem pede e recebe autorização para ir à cidade e buscar socorro para Lucius. Ivy vai impulsionada pelo amor, uma força diante da qual o mundo não tem escolha a não ser se ajoelhar, acredita o pai, Edward Walker, o menos ossificado dos anciãos, no frágil limiar entre a manutenção do status quo e a implosão dos muros virtuais que protegem o reino da "inocência".

A cena final protagoniza uma questão que Shyamalan deixa para o espectador elucidar: a nova geração, Ivy, Lucius e outros, será um dia reconhecida pela manutenção ou transformação daquele meio de vida? As notícias do retorno de Ivy, portando os medicamentos, e de seu triunfo sobre uma das "criaturas" da floresta precede sua chegada ao quarto onde os anciãos velam o moribundo Lucius. Criadores da farsa envolvendo as criaturas e cientes do desaparecimento de Noah com uma das fantasias que alimentava o embuste, os guardiões da "paz" local, os pais de Noah entre eles, lamentam a morte do último, mas veem em sua tragédia a oportunidade de perpetuarem, agora com o "martírio" de um dos moradores, a existência do povoado. Nesse momento, Ivy adentra o quarto, ajoelha-se diante do ferido e toma-lhe as mãos. A jovem capaz de enxergar além do alcance dos olhos está de volta. De modo diferente do que supunha a maioria, as entradas e saídas de Ivy para estabelecer conexões e construir sentidos estão escancaradas.

O que terá acontecido ao povoado depois que os créditos da produção começaram a subir pela tela? O assombro de Ivy diante da humanidade do guarda da cidade, o mesmo que a proveu de medicamentos, terá vida longa? Seria uma irrealidade apostar que a vila jamais voltaria a ser como antes? Não, não seria. Ivy, dramaticamente afetada, autora de sua transformação, respirava agora a mudança, e isso é bastante poderoso.

Há muito que a educação brasileira forceja por deixar o vilarejo e atravessar a floresta sombria. Mas a travessia corre perigo porque um novo retrocesso está sendo arquitetado. Um gigantesco passo atrás. Atrás da floresta, onde mora o atraso, a manipulação, o obscu- 
rantismo, o medo e o despreparo. Lamentavelmente, já em estado adiantado nos corpos e consciências: "Uma distopia do real que pode se intensificar e expandir caso cessemos de apresentar modos de resistência criativos" (GUERREZI, 2015, p. 13).

\section{REFERÊNCIAS}

ARENDT, Hannah. Eichmann em Jerusalén: un estudio acerca de la banalidade del mal. Barcelona: Lúmen, 2003.

BAGDONAS, Alexandre; AZEVEDO, Hernani Luiz. O Projeto de Lei "Escola sem Partido" e o Ensino de Ciências. ALEXANDRIA: Educ. Ci. Tec., Florianópolis, v. 10, n. 2, p. 259-277, nov. 2017.

BALDAN, Merilin. DO PROGRAMA ESCOLA SEM PARTIDO COMO APANÁGIO DO "ÓDIO À DEMOCRACIA" OU COMO PROJETOS NEOCONSERVADORES E LIBERAIS NEGAM A EDUCAÇÃO PARA TODOS. Fênix - Revista de História e Estudos Culturais, v. 14, p. 1-19, jan./jun. 2017.

BARROS, Manoel. Poesia Completa. São Paulo: Leya, 2011.

BIESTA, Gert. Boa Educação na Era da Mensuração. Cadernos de Pesquisa, v. 42, n. 147, p. 808-825, set./dez. 2012.

BRASIL. Câmara dos Deputados. Projeto de Lei $\mathbf{n}^{\mathbf{0}} \mathbf{. 8 7 6}$ de 2015. Inclui entre as diretrizes e bases da educação nacional, o "Programa Escola sem Partido". Brasília (DF), 2015.

BRASIL. Senado Federal. Projeto de Lei $\mathbf{n}^{0} \mathbf{} 193$ de 2016. Inclui entre as diretrizes e bases da educação nacional, o "Programa Escola sem Partido". Brasília (DF), 2015.

CHAUI, Marilena. A universidade pública sob nova perspectiva. Revista Brasileira de Educação, n. 24, p. 5-15, set./out./nov./dez. 2003.

CHAUI, Marilena. O que é ideologia, 2. ed. São Paulo: Brasiliense, 2008.

COSTA, Fabrício Veiga. LIBERDADE DE CÁTEDRA DO DOCENTE NOS CURSOS DE BACHARELADO EM DIREITO: UM ESTUDO CRÍTICO DA CONSTITUCIONALIDADE DO PROJETO DE LEI ESCOLA SEM PARTIDO. Revista Jurídica, Curitiba, v. $1, n^{\circ} .50$, p. $374-397,2018$.

COSTA, Fabrício Veiga. Liquidez e certeza dos Direitos Fundamentais no Processo Constitucional Democrático. Coleção Estudos da Escola Mineira de Processo, v. 1. Rio de Janeiro: Lumen Juris, 2016, 228p. ISBN 9788584407880 
DRESCH, Jaime Farias. QUEM DOUTRINA QUEM? OS PARTIDOS POLÍTICOS E O DISCURSO DA ESCOLA SEM PARTIDO COMO PROCESSO FORMATIVO. Fênix Revista de História e Estudos Culturais, v. 14, p. 1-19, jan.jun. 2017.

ESCOLA SEM PARTIDO. Planeje sua denúncia. Disponível em: http://www.escolasempartido.org/planeje $\square$ sua $\square$ denuncia.

FERNANDES, Maria Dilnéia Espíndola. O PERCURSO POLÍTICO-LEGISLATIVO DO PROGRAMA "ESCOLA SEM PARTIDO" EM CAMPO GRANDE, MS. ETD - Educação Temática Digital Campinas, SP, v. 19, n. esp., p. 217-235, jan./mar. 2017.

FREIRE, Paulo. Pedagogia da Autonomia - Saberes Necessários à Prática Educativa. São Paulo: Paz e Terra, 2007.

FREITAS, Nivaldo Alexandre. ESCOLA SEM PARTIDO COMO INSTRUMENTO DE FALSA FORMAÇÃO. Fênix - Revista de História e Estudos Culturais, v. 14, p. 1-20, jan.jun. 2017.

FRIGOTTO, Gaudêncio. Escola "sem" partido: esfinge que ameaça a educação e a sociedade brasileira (org.) Gaudêncio Frigotto. Rio de Janeiro: UERJ, LPP, 2017.

GUERREZI, Evânio Márlon. Estado e resistência: Deleuze, Guattari e a distopia do real, 2015, 159s. Dissertação (Mestrado em Filosofia). Programa de Pós-Graduação em Filosofia, Universidade Estadual do Oeste do Paraná, Toledo, 2015.

GUILHERME, Alexandre Anselmo; PICOLI, Bruno Antonio Escola sem Partido - elementos totalitários em uma democracia moderna: uma reflexão a partir de Arendt. Rev. Bras. Educ., v. 23, p. 1-23, 2018.

LEITE, Siomara Borba. Considerações em torno do significado do conhecimento. In: MOREIRA, Antônio Flávio Barbosa (Org.). Conhecimento educacional e a formação do professor. São Paulo: Papirus Editora, 1994.

LIMA, Linício. Crítica da educação indecisa: a propósito da pedagogia da autonomia de Paulo Freire. Revista e-curriculum, São Paulo, v. 7, n. 3, dez. 2011.

MACEDO, Elizabeth. AS DEMANDAS CONSERVADORAS DO MOVIMENTO ESCOLA SEM PARTIDO E A BASE NACIONAL CURRICULAR COMUM Educação \& Sociedade, v. 38, n. 139, p. 507-524, abr./jun. 2017.

MONTENEGRO, Oswaldo. “Lua e Flor”. Pérolas. Brasil, Som Livre, 2000, CD.

MOURA, Fernanda Pereira. "Escola Sem Partido": relações entre Estado, educação e religião e os impactos no ensino de história, 189s. Dissertação - (Mestrado Profissional em 
Ensino de História) Instituto de História, Universidade Federal do Rio de Janeiro, Rio de Janeiro, 2016.

NAGIB, Miguel. Escola Sem Partido: quem somos. Disponível em: http://www.escolasempartido.org/quem- somos. Acesso em: 15 mar. 2016.

NETO, José Leite dos Santos; CARDOSO, Henrique Ribeiro. SOBRE A AUTONOMIA UNIVERSITÁRIA, LIBERDADE DE CÁTEDRA E O PROJETO DE LEI "ESCOLA SEM PARTIDO" Revista de Teoria e Filosofia do Estado, Maranhão, v. 3, n. 2, p. 76-94, jul./dez. 2017.

OLIVEIRA, Edna Araujo S.; CERNY, Roseli Zen; ÁVILA, Silviane de Luca. A docência perante o projeto de lei "Escola sem Partido". Revista Educação e Emancipação, São Luís, v. 11, n. 3, p. 250-266, set./dez. 2018.

PARKER, Alan. Pink Floyd the wall [Filme - DVD] Produção de Alan Marshal, Direção de Alan Parker. Reino Unido, Metro-Goldwyn-Mayer, 1982, 95 min. color. son.

PENNA, Fernando. Programa "Escola Sem Partido": Uma ameaça à educação emancipadora. In: GABRIEL, Carmem Tereza; MONTEIRO, Ana Maria; MARTINS, Marcus Leonardo Bomfim (Orgs.). Narrativas do Rio de Janeiro nas aulas de história. Rio de Janeiro: Mauad, p. 43-58, 2016.

PIAGET, Jean. O nascimento da inteligência na criança, 4. ed. Rio de Janeiro: Guanabara, 1987, 392p. ISBN 9788521612582

PIAGET, Jean. Psicologia e pedagogia. Tradução de Dirceu Accioly Lindoso e Rosa Maria Ribeiro da Silva, 4. ed. Rio de Janeiro: Forense Universitária, 1976.

PLAZA, Julio. Arte/ciência: uma consciência. ARS (São Paulo), São Paulo, v. 1, n. 1, p. 37-47, 2003.

PRATA, Ana Rita Souza; Paula Sant'Anna Machado. Apesar de Você, Amanhã Há de Ser Outro Dia: Análise das consequências da efetivação de programas como "Escola sem Partido" Cadernos da Defensoria Pública do Estado de São Paulo. São Paulo, v. 3 n. 8, p. 77-85, fev. 2018.

PUIG, Josep Maria. A construção da personalidade moral. São Paulo: Ática, 1998.

RAMOS, Moacyr Salles; STAMPA, Inez. SUBVERSÃO E RESISTÊNCIA DOCENTE: notas sobre a ditadura militar e o Programa Escola sem Partido. ESPAÇO DO CURRÍCULO, v. 9, n. 2, p. 249-270, mai./ago. 2016. 
REIS, Graça Regina Franco da Silva; CAMPOS, Marina Santos Nunes; FLORES, Renata Lucia Baptista. CURRÍCULO EM TEMPOS DE ESCOLA SEM PARTIDO: hegemonia disfarçada de neutralidade. ESPAÇO DO CURRÍCULO, v. 9, n. 2, p. 200-214, mai./ago. 2016.

REUSER, Ester Maria Dreher. EM TEMPOS DE ESCOLA SEM PARTIDO, PERGUNTEMO-NOS: QUAL A FUNÇÃO DA EDUCAÇÃO EM UMA SOCIEDADE? O QUE CABE À ESCOLA E AO PROFESSOR? ETD - Educação Temática Digital, Campinas, SP, v. 19, n. esp., p. 206-216, jan./mar. 2017.

ROSA, João Guimarães. Primeiras Estórias. Rio de Janeiro: Nova Fronteira, 1988.

SACRISTÁN, J. Gimeno. O currículo: uma reflexão sobre a prática. Porto Alegre: Artmed, 2000.

SANTOS, Milton. Por uma outra globalização: do pensamento único à consciência universal. São Paulo: Record, 2000, 176p. ISBN: 9788501058782

SILVA, Daniel Pinha. AMPLIAÇÃO E VETO AO DEBATE PÚBLICO NA ESCOLA: HISTÓRIA PÚBLICA, ENSINO DE HISTÓRIA E O PROJETO "ESCOLA SEM PARTIDO”. Transversos: Revista de História. Rio de Janeiro, v. 7, n. 7, p. 11-34, set. 2016.

SILVA, Maurício Roberto; DICKMANN, Ivo; BERNARTT, Maria de Lourdes. Radiografia do Golpe, neoliberalismo e destruição do Estado, "apagamento" dos direitos sociais, Educação Temer(ária) e Escola sem Partido. Revista Pedagógica, Chapecó, v. 19, n. 40, p. 7-21, jan./abr. 2017.

SILVEIRA, Viviane Teixeira; CARNEIRO, Kleber Tüxen; ATHAYDE, Thayz. Cinema, educação e violência de gênero: considerações sobre o documentário 'the hunting ground'. Textura, Governador Mangabeira, BA, v. 18, n. 38, p. 162-177, set./dez. 2016.

THIEL, Cristiane Grace; THIEL, Janice. Grace. Movie takes: a magia do cinema na sala de aula. Curitiba, PR: Aymará, 2009. 


\section{Sobre OS AUTORES}

\section{Maurício Bronzatto}

Doutor em Educação Escolar pela Universidade Estadual Paulista/SP-Brasil. Professor do Instituto Federal de Educação, Ciência e Tecnologia de São Paulo.SaltoSP-Brasil. maub1970@gmail.com

\section{Kleber Tüxen Carneiro}

Desenvolve estágio de Pós-Doutoramento junto à Faculdade de Educação da Universidade de Campinas/SP-Brasil. Doutor em Educação Escolar pela Universidade Paulista/SP-Brasil. Professor do Departamento de Educação Física e no Programa de Pós-Graduação em Educação da Universidade Federal de Lavras/MG-Brasil. kleber2910@gmail.com

\section{Eliasaf Rodrigues de Assis}

Doutor em Educação Escolar pela Universidade Estadual Paulista/SP-Brasi. Professor do programa de Pós-Graduação (MBA) em uma instituição privada de Campinas/SP. eliasafassis@gmail.com

Submetido em: 6-5-2019

Aceito em: 1-11-2019 